\title{
Avaliação nutricional na atenção básica à luz dos princípios que fundamentam a organização da atenção nutricional no Sistema Único de Saúde
}

\author{
Nutritional assessment in primary care in light of the underlying \\ principles in the organization of nutritional care in the \\ Brazilian Unified National Health System
}

Evaluación nutricional en la atención básica, a la luz de los principios que fundamentan la organización de la atención nutricional en el Sistema único de Salud

\begin{abstract}
AVALIAÇÃO NUTRICIONAL NA ATENÇÃO BÁSICA: REFLEXÕES SOBRE PRÁTICAS E SABERES. Ferreira AA, Barros DC, Bagni UV, organizadores. Rio de Janeiro: Editora Fiocruz; 2018. 127 p. (Coleção Fazer Saúde). ISBN 97885-7541-622-8.
\end{abstract}

doi: 10.1590/0102-311X00155719

O livro Avaliação Nutricional na Atenção Básica: Reflexões sobre Práticas e Saberes oferece ao leitor uma abordagem ampliada e inovadora de um tema "clássico" no campo da saúde e nutrição - a avaliação nutricional. Possibilita uma releitura dessa temática por meio de reflexões sobre métodos, técnicas e instrumentos diagnósticos à luz dos princípios e diretrizes que fundamentam a organização da atenção nutricional na atenção básica do Sistema Único de Saúde (SUS).

Para tal, os autores problematizam o tema mediante análise do perfil epidemiológico, nutricional e alimentar da população brasileira, em suas inter-relações com o contexto político e institucional do SUS, considerando as desigualdades que marcam o cenário nacional. O significativo peso de influência das doenças crônicas no perfil de morbimortalidade, e sua relação com a obesidade, vem impondo terapêuticas de médio/longo prazo que potencializem a adesão e a permanência dos usuários e que abordem os múltiplos condicionantes psicossociais, culturais e biológicos do processo saúde-doença. A complexidade e a heterogeneidade desse perfil alimentar e nutricional, condicionado por um contexto nacional diverso e desigual, colocam desafios específicos para a garantia da equidade em saúde e nutrição. Considerando esse cenário, a Rede de Atenção à Saúde (RAS) das pessoas com doenças crônicas no SUS foi instituída com base em princípios que qualificam as práticas de saúde, tais como: integralidade; humanização; terapêutica multiprofissional; corresponsabilização profissional/usuário, construção do vínculo, da autonomia do usuário e do autocuidado; intersetorialidade; participação social, respeito às diversidades étnico-raciais, sociais e religiosas, aos hábitos e a cultura locais 1 .

A avaliação nutricional é então problematizada pelos autores à luz desses princípios e a estruturação do material apresentado reflete o caminho percorrido no intuito de construir uma abordagem ampla e integrada das dimensões técnica, epidemiológica, política e institucional dessa prática. Os dois capítulos iniciais discutem o cenário nutricional/epidemiológico, os métodos, técnicas e instrumentos para avaliação do estado nutricional e do consumo alimentar. Cabe ressaltar que, em muitos projetos terapêuticos, o foco do diagnóstico alimentar recai sobre o perfil de consumo propriamente dito (alimentos consumidos, quantidade e frequência). No entanto, a construção de uma terapêutica nutricional adequada, viável de ser operacionalizada no cotidiano, demanda conhecer não apenas o que é consumido, mas também como os alimentos são consumidos e preparados, onde, com quem, em 
quais horários, ou seja, as práticas alimentares mais amplas.

Os três capítulos subsequentes discutem particularidades da avaliação nutricional de pessoas com deficiência; povos e comunidades tradicionais; pessoas em situação de rua e privação de liberdade. A análise dessas situações específicas evidencia os desafios do SUS para garantir o direito à saúde com base nos princípios da universalidade e equidade. As desigualdades em saúde e nutrição, bem como no acesso à RAS, estão fortemente relacionadas com os processos de concentração de renda, bens e serviços públicos que são marcantes no cenário brasileiro. Mais ainda, são condicionadas pelos valores, práticas e trajetórias institucionais de cuidado vivenciadas no cotidiano dos serviços de saúde e com as relações sociais construídas nesse contexto, incluindo aquelas que se estabelecem entre profissionais e usuários do SUS e que podem contribuir para constituir, aceitar, naturalizar e perpetuar as profundas desigualdades existentes no país.

Nos dois últimos capítulos, os autores procuram articular os diferentes conteúdos que são apresentados ao longo do livro, referentes à avaliação nutricional, ao cenário epidemiológico, nutricional/alimentar e às ações que integram a atenção nutricional na atenção básica. Para tal, indicam como a avaliação nutricional e a vigilância alimentar e nutricional contribuem para a organização e execução das práticas de saúde e para o conjunto de ações de promoção da alimentação adequada e saudável que vêm sendo instituídas no país. No sexto capítulo, são destacados os princípios que norteiam as RAS, bem como a relação entre a avaliação nutricional e as ações/modos de atenção à saúde que potencializam esses princípios, tais como: as atividades em grupo; as oficinas culinárias; o cultivo de hortas; a clínica ampliada; a equipe interdisciplinar; os projetos terapêuticos singulares; o planejamento territorial integrado; dentre outros.

Apesar dos avanços na construção de políticas e programas pautados na integralidade do cuidado, no trabalho multiprofissional, na humanização e nos demais princípios aqui destacados, é longo o caminho a ser percorrido para reorientação das práticas de atenção em saúde. Nesse sentido, são problematizados no sexto capítulo os fatores referentes ao contexto institucional e de gestão do SUS que podem dificultar a consolidação da prática de avaliação nutricional na atenção básica, como a formação dos profissionais e a inadequação do espaço físico e dos recursos existentes. Outros desafios abordados ao longo do livro referem-se à necessidade de serem aplicadas medidas antropométricas ou parâmetros de referência alternativos para avaliação nutricional de segmentos específicos, como no caso das pessoas com deficiência física. Há de se distinguir os limites relacionados com os métodos de avaliação nutricional, daqueles referentes ao contexto institucional, de gestão e das práticas de saúde que afetam o conjunto de usuários do SUS ou outros segmentos populacionais específicos, para além dos abordados pelos autores. Como exemplo, a "não adequação de ambientes, mobiliários e equipamentos" (como balanças), que inviabiliza uma avaliação nutricional adequada das pessoas com deficiência, destacada no capítulo três, assim como a "culpabilização dos indivíduos" dos povos e comunidades tradicionais, destacada no capítulo quatro, e a "estigmatização e os preconceitos" relativos às pessoas com deficiência, aos povos e comunidades tradicionais e as pessoas em situação de rua, também vêm sendo identificados em estudos nacionais/internacionais sobre o cuidado à saúde das pessoas com obesidade 2,3 . O preconceito antecipa explicações que rotulam os sujeitos, conforma barreiras e promove conclusões precipitadas e descontextualizadas que, em muitos casos, contribuem para reforçar desigualdades.

Portanto, ao apresentarem os desafios para a avaliação nutricional de segmentos populacionais específicos, os autores contribuem para problematizar as barreiras mais amplas para inclusão equitativa no SUS e sinalizam caminhos possíveis para a reorientação dos modos de prestação de cuidado na perspectiva da universalidade e da equidade. Tais caminhos reforçam a relevância dos princípios já pautados na RAS das pessoas com doenças crônicas 1 e indicam como o projeto terapêutico singular, que considera os condicionantes específicos do processo saúdedoença em cada contexto geopolítico e territorial e as particularidades dos sujeitos, é fundamental para a integralidade do cuidado. Tal perspectiva contribui para superar as dicotomias entre a culpabilização $v s$. vitimização e entre condicionantes individuais $v s$. ambientais do processo saúde-doença. 
Por fim, ao abordarem a avaliação nutricional no contexto da atenção integral em saúde e das políticas de promoção da alimentação adequada e saudável, os autores estimulam os profissionais de saúde a reconhecerem a transversalidade e a relevância dessa prática e, consequentemente, fomentá-la em seu cotidiano de trabalho..

\section{Luciene Burlandy 1}

1 Universidade Federal Fluminense, Niterói, Brasil. burlandy@uol.com.br

\section{Informação adicional}

ORCID: Luciene Burlandy (0000-0003-0875-6374).

1. Ministério da Saúde. Portaria no 483, de 1o de abril de 2014. Redefine a Rede de Atenção à Saúde das Pessoas com Doenças Crônicas no âmbito do Sistema Único de Saúde (SUS) e estabelece diretrizes para a organização das suas linhas de cuidado. Diário Oficial da União 2014; 2 abr.

2. Francisco LV, Diez-Garcia RW. Abordagem terapêutica da obesidade: entre conceitos e preconceitos. Demetra 2015; 10:705-16.

3. Teixeira FV, Pais-Ribeiro JL, Maia AC. Beliefs and practices of healthcare providers regarding obesity: a systematic review. Rev Assoc Med Bras 2012; 58:254-62. 